\title{
Brewing practices to maximise levels of catechins and other compounds with functional properties in Azorean green tea infusions: comparison with composition of canned green tea drinks
}

\author{
Catarina Petisca, ${ }^{*}$ Armindo Melo, ${ }^{\dagger}$ Isabel M. P. L. V. O. Ferreira ${ }^{\dagger}$ and Olívia Pinho* ${ }^{\dagger}$ \\ *Faculdade de Ciências da Nutrição e Alimentação da Universidade do Porto, Rua Dr. Roberto Frias, \\ 4200-465 Porto, Portugal; ${ }^{\dagger}$ REQUIMTE, Serviço de Bromatologia, Faculdade de Farmácia da \\ Universidade do Porto, Rua Anibal Cunha 164, 4099-030 Porto, Portugal
}

Correspondence:

Isabel Ferreira, Faculdade

de Farmácia,

Universidade do Porto, R Anibal Cunha 164, 4050-047 Porto,

Portugal.

Tel: +351 222078929 ;

Fax: +3512220 03977;

E-mail:

isabel.ferreira@ff.up.pt

Keywords:

caffeine, catechins, gallic acid, green tea, HPLC/

$\mathrm{DAD}$, theophylline

\begin{abstract}
The influence of infusion time, temperature and water characteristics on catechins, gallic acid, theophylline and caffeine levels of Azorean green tea infusions was evaluated in two samples of green tea presenting different compositions to optimise brewing practices and maximise levels of compounds with functional properties in infusions. Additionally, the compounds under study were quantified in commercial canned green tea drinks and levels compared with composition of home-made infusions. An enhancement of epigallocatechin gallate, epigallocatechin and epicatechin gallate levels, the catechins with higher antioxidant activity, was observed as water $\mathrm{pH}$ decreased and infusion time increased. No correlations were found between the levels of gallic acid, theophylline and caffeine of tea infusions, and water $\mathrm{pH}$. The industry of canned green tea drinks produces beverages with a composition of catechins and other bioactive compounds similar to that of home-made acidified green tea with 10-min infusion.
\end{abstract}

\section{Introduction}

Green tea is rich in possibilities as a functional food and is a popular beverage among the new health-conscious generation. Research has started to remove the veil concealing some of its true power as a functional food as attention is being paid to the role of green tea in bioregulating functions (McKay \& Blumberg 2002; Erba et al. 2005; Williamson \& Manach 2005; Cabrera et al. 2006); namely, biodefense function by preventing cancer (McKay \& Blumberg 2002; Wu \& Wei 2002; Higdon \& Frei 2003; Lambert \& Yang 2003; Horie et al. 2005; Shimizu et al. 2005; Arts 2008; Ashihara et al. 2008; Wang et al.
2008), disease-preventing function by preventing high blood pressure or diabetes, disease-recovery function by inhibiting the rise of cholesterol and inflammatory activity (Wang \& Helliwell 2000; McKay \& Blumberg 2002; Ashihara et al. 2008), physical rhythm-controlling function by stimulating the central nervous system with caffeine and ageing-suppressing function by providing the body with antioxidants (McKay \& Blumberg 2002; Jeong \& Kong 2004; Bunkova et al. 2005; Kuzuhara et al. 2006; Kotani et al. 2007; Raza \& John 2007).

Tea is an infusion of Camellia sinensis (L.) leaves. The tea plant, originally from south-east China, gradually expanded to India, Sri Lanka and 
further into many tropical and subtropical countries. Since the last decade of the 19th century, tea is also produced in one unique place in Europe -S. Miguel - Azores Islands (Baptista et al. 1999).

Green tea, black tea and oolong tea are the three major forms of tea. Black tea constitutes $78 \%$ of tea produced worldwide, whereas green tea and oolong tea constitute about 20 and $2 \%$, respectively. Among the three main types of commercial teas, green tea is a type of unfermented tea that preserves a higher quantity of compounds with physiological activity than oolong (semi-fermented) and black (fermented) teas. Green tea has received much attention owing to its health properties. The pharmacological properties are mainly because of the presence of catechins, which constitute up to $30 \%$ on a dry weight basis, are water soluble and can be easily extracted in infusions. The ratio and quantity of catechins determine the taste and quality of the teas. The eight catechins present in green tea and known to possess biological properties are (-)-catechin (C), (-)-epicatechin (EC), (-)gallocatechin (GC), (-)-epigallocatechin (EGC), (-)-gallocatechin gallate (GCG), epigallocatechin gallate (EGCG), (-)-catechin gallate (CG) and (-)epicatechin gallate (ECG) (Sigma Chemical Co., St. Louis, MO, USA). EGCG is regarded as the most important of the tea catechins because of its high content in tea and the fact that its activity is mirrored by green tea extracts. In green tea infusions, catechins undergo many chemical changes such as oxidation and epimerisation, the predominant change appears to be epimerisation from the epistructure to the nonepistructure and water composition can influence these changes (Wang \& Helliwell 2000). Other bioactive compounds from tea include gallic acid and the methylxanthines theophylline and caffeine (Sigma Chemical Co.). Gallic acid is one of the most important phenolic acids present in tea, and it exhibits antioxidant property, anticarcinogenic effect and antifungal activity.

The amount of catechins, gallic acid, theophylline and caffeine extracted depends upon the genetic characters, season, age of the leaves, agronomic condition, the manufacture style, type of water used to prepare the tea and the temperature and duration of infusion.
If tea catechins were epimerised or changed during brewing, then the real profiles of catechin compositions of samples would not be reflected and the healthy functions of the tea extracts would differ from those of the tea itself (Horie et al. 1997). Thus, domestic preparation of 'a cup of tea' may significantly affect the composition and expected health benefits of the drink. It is important, therefore, to understand the fate of catechins, gallic acid, theophylline and caffeine in tea infusions prepared under controlled domestic conditions using different types of water and different temperatures to find an appropriate method for extraction of tea catechins and other bioactive compounds from tea to improve its functional properties.

For several years, manufacturers have been trying to package green tea extract in cans or glass bottles that can be sold as functional drinks. However, it was noted that the production of green tea extract in cans was more problematic than that of black or oolong tea extracts (Watanabe et al. 1998). Functional canned green tea products are relatively new, and there has been only limited information available on processed green tea extracts (Liang et al. 2001).

The objectives of the present study are the following: (i) study the influence of infusion time, temperature and water characteristics on catechins and other bioactive compounds of Azorean green tea infusion to optimize brewing practices and maximise levels of catechins and other compounds with functional properties in green tea infusions, and, (ii) additionally, levels of catechins, gallic acid, theophylline and caffeine in commercial canned green tea drinks were compared with composition of homemade green tea infusions.

\section{Materials and methods}

\section{Chemicals}

Catechins, including C (>98\%), EC (>98\%), GC (>98\%), EGC, CG (>98\%), GCG (>98\%), ECG $(>98 \%)$ and EGCG (>98\%), gallic acid, theophylline $(>99 \%)$ and caffeine for High Performance Liquid Chromatography (HPLC) references were provided by Sigma Chemical Co.

External calibration was used for quantification. Calibration curves were performed in the 
range of $0.5-5 \mu \mathrm{g} / \mathrm{mL}$ for caffeine, gallic acid and theophylline; $1-10 \mu \mathrm{g} / \mathrm{mL}$ for EC; $2.5-20 \mu \mathrm{g} / \mathrm{mL}$ for C, ECG and CG; and 15-60 $\mu \mathrm{g} / \mathrm{mL}$ for GCG, GC, EGC and EGCG. Other reagents and HPLC grade solvents were from Merck (Darmstadt, Germany). HPLC solvents were filtered through $0.22-\mu \mathrm{m}$ NL Nylon Membrane Filters (Whatman, Maidstone, UK).

\section{Sampling}

\section{Green tea infusions}

First experiments were performed with six samples of green tea from Azores Islands (Gorreana) from different lots commercially available. The leaf size was $5-7 \mathrm{~mm}$. The ranges of concentration of catechins, theophylline, caffeine and gallic acid were evaluated, aiming to select the two samples (A and B) presenting maximum and minimum levels of the compounds under study. The assays were performed in 18 infusions: $2 \mathrm{~g}$ of green tea leaves was brewed in $250 \mathrm{~mL}$ of deionised water $(\mathrm{pH} 6.90)$ at $100^{\circ} \mathrm{C}$ for 3,5 and $10 \mathrm{~min}$.

Further experiments were carried out to evaluate the influence of infusion conditions on catechins, theophylline, caffeine and gallic acid extraction: $2 \mathrm{~g}$ of green tea leaves (named as A and $\mathrm{B}$ samples) was brewed in $250 \mathrm{~mL}$ of deionised water $(\mathrm{pH}$ 6.90), tap water $(\mathrm{pH} 7.85)$, mineral water ( $\mathrm{pH} 5.67)$ and mineral water acidified $(\mathrm{pH} 4.4)$ with seven drops of lemon juice at $100^{\circ} \mathrm{C}$ and $90^{\circ} \mathrm{C}$ for 3,5 and $10 \mathrm{~min}$. Samples were codified as follows: 1A3, 1A5, 1A10, 1B3,
1B5 and 1B10 correspond to 3-, 5- and 10-min infusions in acidified mineral water of samples $\mathrm{A}$ and $\mathrm{B}$ respectively. 2A3, 2A5, 2A10, 2B3, 2B5 and 2B10 correspond to 3-, 5- and 10-min infusions in deionised water of samples $\mathrm{A}$ and $\mathrm{B}$ respectively. 3A3, 3A5, 3A10, 3B3, 3B5 and 3B10 correspond to 3-, 5- and 10-min infusions in mineral water of samples $A$ and $B$ respectively. 4A3, 4A5, 4A10, 4B3, 4B5 and 4B10 correspond to 3-, 5- and 10-min infusions in tap water of samples A and B respectively (Table 1 ). The samples were then filtered through a $0.45-\mu \mathrm{m}$ polyester filter and analysed directly by HPLC.

\section{Canned soft drinks with green tea}

Six canned green tea drinks from four different brands (named C to F) commercially available were studied. C1 was a soft drink with green tea and citrus [ingredients: water, green tea extract $(8.4 \%)$, lemon juice $(0.2 \%)$, aromas, fructose, caffeine, acidifier and sweeteners]. C2 was a soft drink with green tea [ingredients: water and green tea extract $(5.3 \%)$, sugar, fructose, aromas, acidifier and ascorbic acid]. D1 was a soft drink with green tea and lemon [ingredients: water, sugar, lemon juice $(0.5 \%)$, green tea extract $(0.1 \%)$, acidifier and preservatives, and sweeteners]. D2 was a nectar of orange, kiwi and green tea [ingredients: water, juice and pulp of orange $(29 \%)$ and kiwi $(11 \%)$, green tea extract $(0.12 \%)$, ascorbic acid and sweeteners]. E was a soft drink of green tea and pear [ingredients: mineral water $(98.5 \%)$, fibre $(1.0 \%)$, dextrin $(0.1 \%)$, natural aromas,
Table 1 Presents study design for optimization of brewing practices to maximise levels of green tea bioactive compounds

\begin{tabular}{llcl}
\hline Samples & $\begin{array}{l}\text { Temperature } \\
\left({ }^{\circ} \mathrm{C}\right)\end{array}$ & $\begin{array}{l}\text { Infusion time } \\
(\mathrm{min})\end{array}$ & $\begin{array}{l}\text { Water } \\
\mathrm{pH}\end{array}$ \\
\hline 1A3/1B3 & $100 / 90$ & 3 & 4.4 \\
1A5/1B5 & $100 / 90$ & 5 & 4.4 \\
1A10/1B10 & $100 / 90$ & 10 & 4.4 \\
2A3/2B3 & $100 / 90$ & 3 & 6.9 \\
2A5/2B5 & $100 / 90$ & 5 & 6.9 \\
2A10/2B10 & $100 / 90$ & 10 & 6.9 \\
3A3/3B3 & $100 / 90$ & 3 & 5.67 \\
3A5/3B5 & $100 / 90$ & 5 & 5.67 \\
3A10/3B10 & $100 / 90$ & 3 & 5.67 \\
4A3/4B3 & $100 / 90$ & 5 & 7.85 \\
4A5/4B5 & $100 / 90$ & 10 & 7.85 \\
4A10/4B10 & $100 / 90$ & & 7.85 \\
\hline
\end{tabular}


acidifier and sweeteners]. F was a carbonated soft drink of lemon and green tea [ingredients: mineral carbonated water, apple concentrate and lemon juice $(2.3 \%)$, acidifier, lemon aroma and green tea extract].

\section{HPLC analysis}

The chromatographic analysis was carried out in an analytical HPLC unit (Jasco, Tokyo, Japan) equipped with two Jasco PU-2080 HPLC pumps, a Column Heater (Model 7981; Jones Chromatography, Hengoed, UK), an MD-2010 Plus multiwavelength detector and a Jasco As-950 intelligent sampler. The column was a reversed-phase Waters Spherisorb $^{\circledR}$ C18 $(5 \mu \mathrm{m}, \quad 250 \mathrm{~mm} \times 4.6 \mathrm{~mm})$ ODS2 (Waters, Milford, MA, USA). The Borwin PDA Controller Software (JMBS Developments, Le Fontanil, France) was also used. The HPLC was carried out according to Liang et al. (2001, 2007). Gradient elution was carried out with a mixture of two solvents and a flow of $1 \mathrm{~mL} / \mathrm{min}$. Solvent A consisted of acetonitrile/acetic acid/water (6:1:193, v:v:v) and solvent B consisted of acetonitrile/acetic acid/water $(60: 1: 139, \mathrm{v}: \mathrm{v}: \mathrm{v})$, changing from $100 \%(\mathrm{v})$ solvent A to $100 \%$ (v) solvent $\mathrm{B}$ by linear gradient during the first $40 \mathrm{~min}$, returning to initial conditions. Detection was performed at $280 \mathrm{~nm}$.

\section{Data analysis}

The tests were carried out in duplicate for each sample. SPSS for Windows, v. 16 (SPSS Inc., Chi- cago IL, USA) was used for statistical treatment of results. Quantitative data from the HPLC analysis were compared using analysis of variance. For variables for which significant $F$ values $(P<0.05)$ were found, Tukey test was used for comparison means. The calculations of the correlation coefficients between the levels of catechins, gallic acid, theophylline and caffeine of different tea samples and the infusion time were those of Pearson. Principal components analysis (PCA) was performed using catechins concentrations as variables, in order to reduce the dimensionality of the data, and pinpoint the most important effects of influence of water type on green infusion composition.

\section{Results and discussion}

\section{Evaluation of ranges of concentration of} catechins, theophylline, caffeine and gallic acid in Azorean green tea

First studies were performed using tea infusions prepared with $2 \mathrm{~g}$ of green tea leaves brewed in $250 \mathrm{~mL}$ of deionised water at $100^{\circ} \mathrm{C}$ for 3,5 and $10 \mathrm{~min}$, a usual practice in Western countries. A typical chromatogram is shown in Fig. 1. The content of catechins, theophylline, caffeine and gallic acid varied significantly $(P<0.05)$ in the samples analysed. Table 2 presents the ranges of concentration for each compound according to the conditions used. The Azorean tea is processed between April and September, and the amount of catechins is higher in Summer than in Spring,

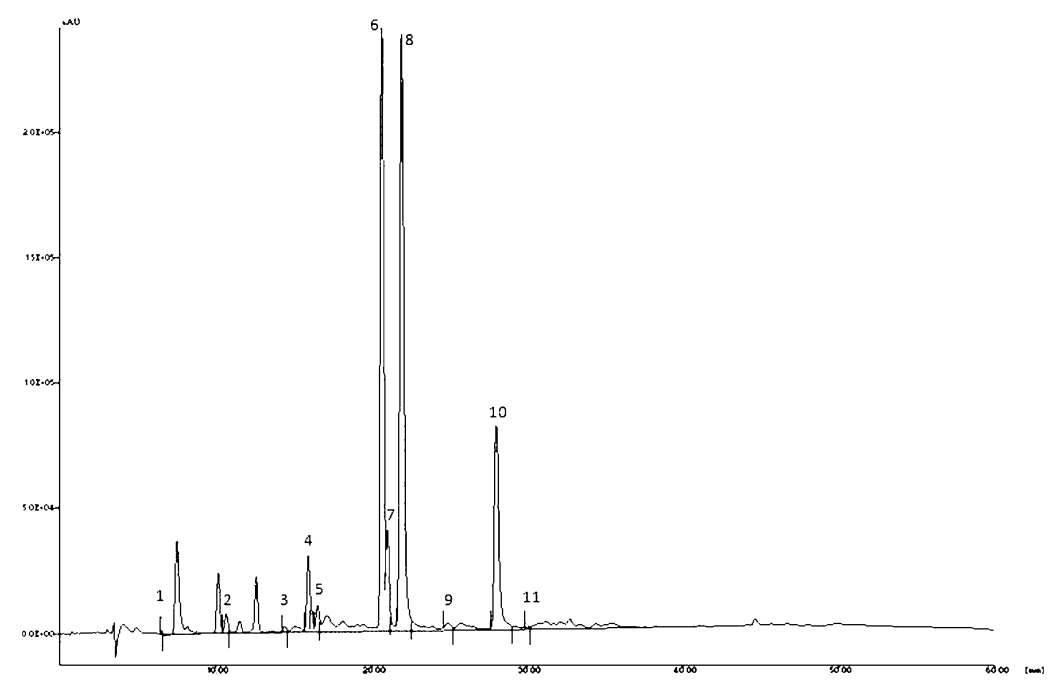

Figure 1 Chromatogram of the analysed compounds. 1-Gallic acid; 2-Gallocatechin; 3-Theophylline; 4-Epigallocatechin; 5-Catechin; 6-Caffeine; 7-Epicatechin; 8 -Epigallocatechin gallate; 9-Gallocatechin gallate; 10-Epicatechin gallate; 11-Catechin. 
Table 2 Ranges of concentration for catechins, theophylline (TP), caffeine (CAF) and gallic acid (GA) in tea infusions prepared with $2 \mathrm{~g}$ of tea brewed in $250 \mathrm{~mL}$ of deionised water at $100^{\circ} \mathrm{C}$ for three different infusion times

\begin{tabular}{|c|c|c|c|c|}
\hline \multirow{2}{*}{$\begin{array}{l}\text { Compounds } \\
(\mathrm{mg} / \mathrm{g})\end{array}$} & \multicolumn{4}{|c|}{ Infusion time (min) } \\
\hline & $3(n=6)$ & $5(n=6)$ & $10(n=6)$ & Pearson correlation* $(P)$ \\
\hline $\mathrm{C}$ & $0.48-0.88$ & $0.72-2.15$ & $1.07-2.96$ & 0.695 \\
\hline $\mathrm{EC}$ & $1.57-2.55$ & $1.93-3.42$ & $2.35-4.31$ & 0.641 \\
\hline GC & $0.22-0.58$ & $0.27-0.69$ & $0.49-0.71$ & 0.290 \\
\hline EGC & $8.78-11.34$ & $10.32-19.50$ & $13.66-27.31$ & 0.636 \\
\hline GCG & $0.49-1.15$ & $0.72-2.68$ & $1.09-3.78$ & 0.528 \\
\hline EGCG & $5.64-13.23$ & $7.07-24.88$ & $9.90-31.35$ & 0.539 \\
\hline CG & $0.74-1.51$ & $0.89-2.03$ & $1.15-2.10$ & 0.529 \\
\hline ECG & $2.44-5.72$ & $2.93-7.86$ & $4.01-9.64$ & 0.578 \\
\hline GA & $0.36-0.73$ & $0.41-1.08$ & $0.52-1.25$ & 0.573 \\
\hline $\mathrm{TP}$ & $0.12-0.27$ & $0.14-0.40$ & $0.20-0.50$ & 0.638 \\
\hline CAF & $4.40-11.76$ & $4.68-13.52$ & $4.81-14.37$ & 0.584 \\
\hline
\end{tabular}

*Pearson correlation between levels of the compounds under study and the infusion time.

GC, (-)-gallocatechin; EGC, (-)-epigallocatechin; C, (-)-catechin; EC, (-)-epicatechin; EGCG, (-)-epigallocatechin gallate; GCG, (-)-gallocatechin gallate; ECG, (-)-epicatechin gallate; CG, (-)-catechin gallate.

presumably because of the higher growth rate and metabolic activities of the young leaves during that season (Baptista et al. 1999), which explains the high variability of catechins and other bioactive compounds found in samples from the market. Additionally, catechins are used by plants to protect them against ultraviolet visible light. Seasonal effects were also reported in Australian tea (Yao et al. 2005) and in northeastern Indian tea (Singh et al. 1999; Reto et al. 2007) in which the EGCG, EGC and ECG contents rose during the warm season and fell during the cold season. Variations in the caffeine content according to the origin of the leaf, type of soil and manufacturing conditions are usual (Chen et al. 1998).

Levels of catechins, gallic acid, theophylline and caffeine of different tea samples were positively correlated with the infusion time (Pearson correlation) and significant at 0.05 level for C, EC, EGC, GCG, EGCG, CG, ECG, gallic acid, theophylline and caffeine. Only GC correlations were significant at 0.01 level $(P=0.290)$. Thus, increasing infusion time results in an increasing of concentration of the compounds under study.

Influence of infusion conditions on catechins, theophylline, caffeine and gallic acid extraction

Two samples of green tea presenting very different compositions were selected from those analysed previously (named as A and B, as can be observed in Fig. 2) and used for further studies of influence of infusion conditions on catechins, theophylline, caffeine and gallic acid extraction. Sample A presented significantly higher levels of all the compounds under study when compared with sample B. The most abundant catechin in sample A is EGCG, followed by EGC, whereas in sample $B$ the most abundant catechin is EGC, followed by EGCG. The third most abundant catechin in both samples was ECG.

Different types of water were tested, including deionised water, mineral water, mineral water acidified with lemon juice and tap water at three different infusion times $(3,5$ and $10 \mathrm{~min})$ at $100^{\circ} \mathrm{C}$. The assays were repeated at $90^{\circ} \mathrm{C}$ as these are the usual conditions for tea brewing in Western countries. PCA was performed using catechin levels at $100^{\circ} \mathrm{C}$ as variables in order to reduce the dimensionality of the data and pinpoint the most important effects of water type and infusion time on the catechin extraction and changes as a result of epimerisation and oxidation. Another PCA was performed using catechin levels at $90^{\circ} \mathrm{C}$ as variables.

As shown in Table 3, communalities among the variables were high, ranging from 0.528 to 0.983 for experiments performed at $100^{\circ} \mathrm{C}$, and from 0.773 to 0.987 for experiments performed 


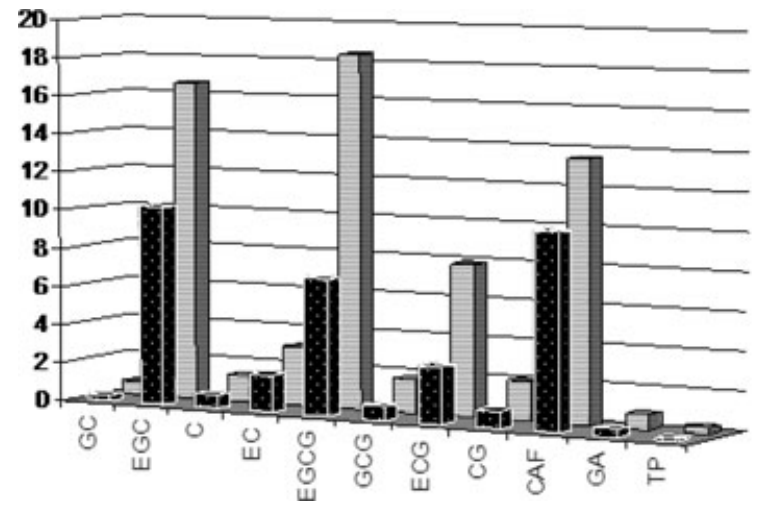

Figure 2 Catechins, theophylline (TP), caffeine (CAF) and gallic acid (GA) contents of two samples (A and $\mathrm{B})$ of Azorean green tea brewed in deionised water at $100^{\circ} \mathrm{C}$ during 5 min.

GC, (-)-gallocatechin; EGC, (-)epigallocatechin; C, (-)-catechin; EC, (-)-epicatechin; EGCG, (-)epigallocatechin gallate; GCG, $(-)$-gallocatechin gallate; ECG, (-)-epicatechin gallate; CG, $(-)$-catechin gallate.

Table 3 Principal components loadings for catechin levels in two sets of experiments, one at $100^{\circ} \mathrm{C}$ and another at $90^{\circ} \mathrm{C}$

\begin{tabular}{|c|c|c|c|c|c|c|}
\hline \multirow[b]{2}{*}{ Catechins } & \multicolumn{3}{|c|}{ Experiments at $100^{\circ} \mathrm{C}$} & \multicolumn{3}{|c|}{ Experiments at $90^{\circ} \mathrm{C}$} \\
\hline & PC1 & PC2 & Communalities & PC1 & PC2 & Communalities \\
\hline C & 0.650 & 0.738 & 0.968 & 0.521 & 0.842 & 0.987 \\
\hline EC & 0.949 & 0.259 & 0.969 & 0.790 & 0.544 & 0.773 \\
\hline GC & 0.721 & 0.090 & 0.528 & 0.816 & -0.065 & 0.695 \\
\hline EGC & 0.961 & 0.166 & 0.952 & 0.938 & 0.032 & 0.860 \\
\hline GCG & 0.173 & 0.979 & 0.989 & 0.021 & 0.994 & 0.969 \\
\hline EGCG & 0.897 & 0.246 & 0.866 & 0.939 & 0.135 & 0.864 \\
\hline CG & 0.174 & 0.976 & 0.983 & 0.005 & 0.992 & 0.957 \\
\hline ECG & 0.840 & 0.447 & 0.904 & 0.843 & 0.482 & 0.924 \\
\hline
\end{tabular}

GC, (-)-gallocatechin; EGC, (-)-epigallocatechin; C, (-)-catechin; EC, (-)-epicatechin; EGCG, (-)-epigallocatechin gallate; GCG, (-)-gallocatechin gallate; ECG, (-)-epicatechin gallate; CG, (-)-catechin gallate.

at $90^{\circ} \mathrm{C}$. Similar catechin performance was observed for experiments conducted at $100^{\circ} \mathrm{C}$ and at $90^{\circ} \mathrm{C}$ as shown in Table 3 .

The results of PCA at $100^{\circ} \mathrm{C}$ are depicted on a two-dimensional plot (Fig. 3 ) that is able to explain $87.9 \%$ of the total variance. Component 1 explains $45.6 \%$ of the variance in the data; the positive segment of the plot for this component is closely related to the levels of GC, EGC, EC, EGCG and ECG as can be concluded from analysis in Table 3. Component 2 explains $42.2 \%$ of the variance in the data; this dimension is positively related to levels of C, GCG and CG. In this figure, the catechins needed for the definition of these components are shown on the axis edges, indicating the direction in which their levels increase. Infusions with the same type of water clustered together. Three clusters were obtained, one for tap water infusions (including 3-, 5- and 10-min infusion times of samples A and B), another for mineral water and deionised water infusions (also for 3-, 5and 10-min infusions for the two samples) and the third for acidified mineral water infusions. Thus, water $\mathrm{pH}$ influenced catechins' extraction and changes in their composition. Figure 3 shows that, by using boiling tap water, the content of the non-epistructured catechins, such as C, GCG and CG, increased, except GC, while the content of the epistructured catechins, namely EGC, EC, EGCG and ECG, decreased when compared with using boiling deionised water or boiling mineral water. When compared with acidified mineral water infusion, this effect was even more notorious. This indicates that, during the tea-infusion process, the epimerisation of the catechins occurs more readily when using boiling tap water. Samples A and B presented different catechin contents, however; they showed similar 'behaviour' in the four types of 


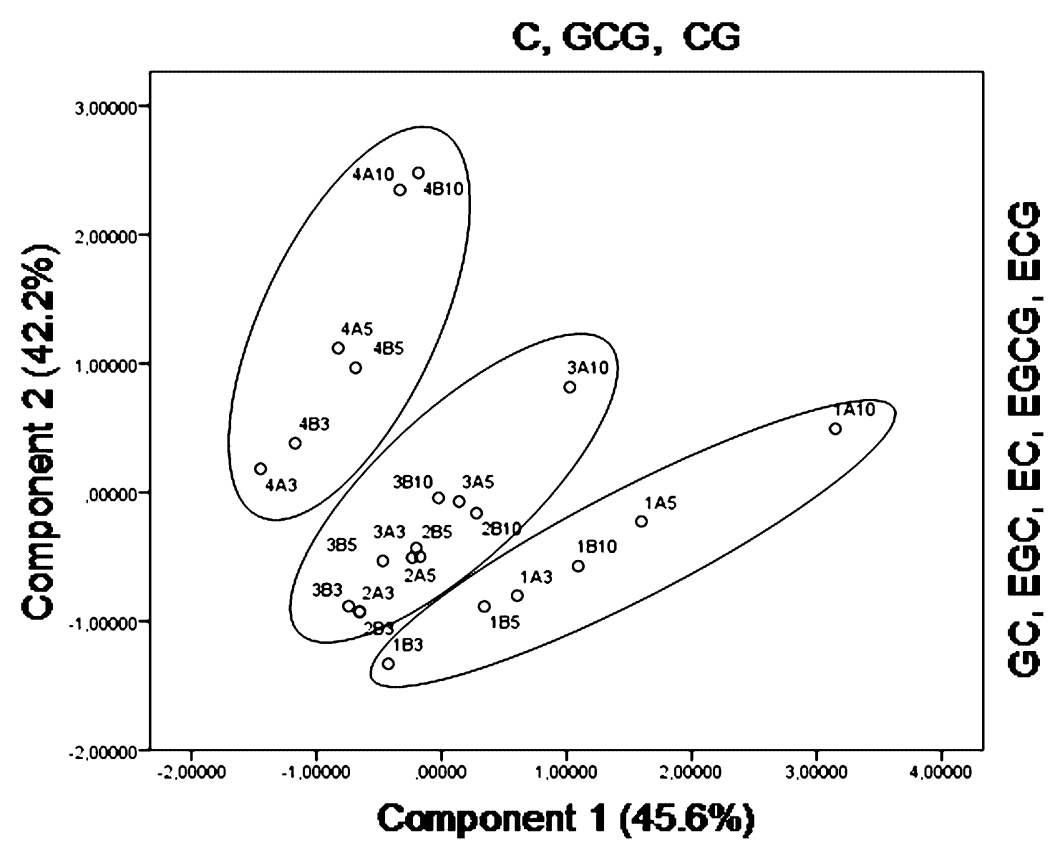

Figure 3 Two-dimensional plot representing the principal components analysis of data from catechins at $100^{\circ} \mathrm{C}$ infusions. $1 \mathrm{~A} 3,1 \mathrm{~A} 5,1 \mathrm{~A} 10,1 \mathrm{~B} 3,1 \mathrm{~B} 5$ and $1 \mathrm{~B} 10$ correspond to 3-, 5- and 10-min infusions in acidified mineral water of samples $\mathrm{A}$ and $\mathrm{B}$, respectively. 2A3, 2A5, 2A10, 2B3, 2B5 and 2B10 correspond to 3-, 5- and 10-min infusions in deionised water of samples $\mathrm{A}$ and $\mathrm{B}$ respectively. 3A3, 3A5, 3A10, 3B3, 3B5 and 3B10 correspond to 3-, 5- and 10-min infusions in mineral water of samples $A$ and $B$ respectively. 4A3, 4A5, 4A10, 4B3, 4B5 and 4B10 correspond to 3-, 5- and 10-min infusions in tap water of samples $\mathrm{A}$ and $\mathrm{B}$ respectively.

GC, (-)-gallocatechin; EGC, (-)-epigallocatechin; C, (-)-catechin; EC, (-)-epicatechin; EGCG, (-)-epigallocatechin gallate; GCG, (-)-gallocatechin gallate; ECG, (-)-epicatechin gallate; CG, (-)-catechin gallate.

water at different infusion times. This is consistent with the results given by other authors (Wang and Helliwell 2000), who observed that epimerisation takes place more easily in tap water than in purified water. The different $\mathrm{pH}$ values between tap (7.85), deionised (6.90) and acidified mineral (4.4) waters are thought to be the main reasons for the different conversion rates for individual catechins (Toschi et al. 2000). Chen et al. (1998) described that, for the $\mathrm{pH}$ ranging from 4 to 7 , the stability of green tea catechins was inversely associated with the $\mathrm{pH}$ value of the infusions.

Toschi et al. (2000) had observed that the antioxidant activity of the green tea is higher in the teas that contain higher levels of EGCG, EGC and ECG. These epimers are major tea components with functional properties. Tea infusions prepared with lemon acidified mineral water during higher infusion times (1A10 and 1B10) presented higher levels of these compounds indicating that infusions of high antioxidant activity were produced.
Levels of gallic acid, theophylline and caffeine of tea infusions obtained in different types of water were positively correlated with the infusion time (Pearson correlation) and significant at 0.05 level, with $P$-values of $0.659,0.690$ and 0.759 , respectively. No correlations were found between the levels of these compounds and water $\mathrm{pH}$.

\section{Analysis of commercial canned green tea drinks}

Individual eight catechins, gallic acid, theophylline and caffeine in commercial canned green tea soft drinks were analysed as shown in Fig. 4. All the catechins under study, gallic acid, theophylline and caffeine were detected in samples C1, C2, D1 and D2 as expected in samples containing green tea extracts. The concentrations of EGC and EGCG were, respectively, the highest quantity contained in these samples. Sample C1 was enriched in EGC, EGCG, ECG and caffeine when compared with $1 \mathrm{~A} 10$ and $1 \mathrm{~B} 10$ samples (infusions in acidified mineral water $10 \mathrm{~min}$ ). C2 


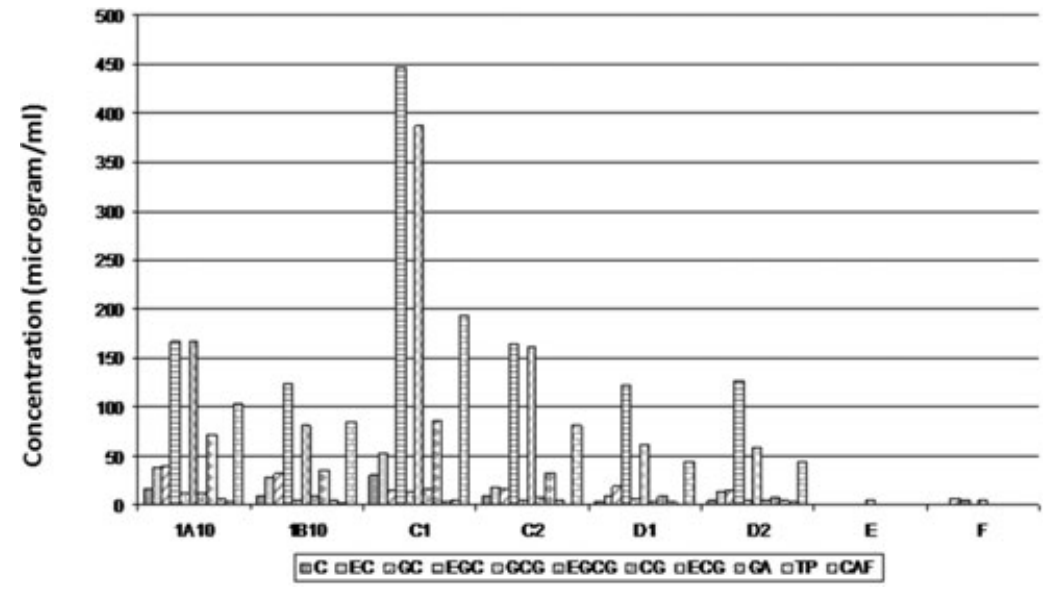

Figure 4 Catechins, gallic acid (GA), theophylline (TP) and caffeine (CAF) contents of tea infusion (1A10 and 1B10) and commercial canned green tea drinks (C1, C2, D1, D2, E and F samples).

GC, (-)-gallocatechin; EGC, (-)epigallocatechin; C, (-)-catechin; EC, (-)-epicatechin; EGCG, (-)epigallocatechin gallate; GCG, (-)-gallocatechin gallate; ECG, (-)-epicatechin gallate; CG, $(-)$-catechin gallate. samples were similar to $1 \mathrm{~A} 10$ samples, and D1 and D2 samples were similar to $1 \mathrm{~B} 10$ sample. It was found that catechin content of some canned drinks was similar when compared with that of tea usually prepared in a tea cup, traditionally prepared by pouring hot water $(250 \mathrm{~mL}$, $90-100^{\circ} \mathrm{C}$ ) onto $2 \mathrm{~g}$ of dry tea leaves in a tea cup during 5- to 10-min infusion. The industry uses the stabilising effect of ascorbic acid and other acidifying agents on catechin stabilisation.

Concerning $\mathrm{E}$ and $\mathrm{F}$ samples of soft drinks with mineral and carbonated water and mentioning the addition of green tea extracts, only three catechins were detected. Sample E contained EGCG and traces of GCG and ECG. Sample F contained GC, EGC and EGCG. Gallic acid, theophylline and caffeine were not detected in those samples. The chromatographic profile of these two samples was not characteristic of the presence of green tea extracts; hence this evaluation can be used as an authenticity parameter to guarantee the conformity with labelling.

\section{Conclusions}

The type of water used to prepare green tea infusion is of critical importance. As expected, there are other factors to consider such as the temperature and the time of infusion. An enhancement of EGCG, EGC and ECG levels, the catechins with higher antioxidant activity, is observed as water $\mathrm{pH}$ decreases and infusion time increases. Thus, the use of mineral water with $\mathrm{pH}$ lower than 7 is advised. Additionally, the levels of EGCG, EGC and ECG can be increased by the addition of a lemon juice or a lemon slice before tea brewing. Temperatures between $90^{\circ} \mathrm{C}$ and $100^{\circ} \mathrm{C}$ are appropriate for tea brewing during $10 \mathrm{~min}$, to enable extraction of great amounts of bioactive compounds.

The canned green tea drinks industry produces beverages with compositions of catechins similar to that of home-made acidified green tea infusion and uses the stabilising effect of ascorbic acid and other acidifying agents for that purpose.

Quantification of catechins, gallic acid, theophylline and caffeine in canned drinks labelled as containing green tea can be used as an authenticity parameter to guarantee the conformity with labelling.

In conclusion, this work indicated tea brewing practices to obtain an infusion rich in bioactive compounds, conveying health messages to consumers and food service professionals. Additionally, comparison of canned green tea drink and home-made green tea infusions provide useful information for the tea industry, legal regulators of food authenticity and consumers.

\section{References}

Arts IC (2008). A review of the epidemiological evidence on tea, flavonoids, and lung cancer. The Journal of Nutrition 138:1561S-6S.

Ashihara H, Sano H, Crozier A (2008). Caffeine and related purine alkaloids: biosynthesis, catabolism, function and genetic engineering. Phytochemistry 69:841-56.

Baptista JAB, Tavares JFP, Carvalho RCB (1999). Comparative study and partial characterization of 
Azorean green tea polyphenols. Journal of Food Composition and Analysis 12:273-87.

Bunkova R, Marova I, Nemec M (2005). Antimutagenic properties of green tea. Plant Foods for Human Nutrition 60:25-9.

Cabrera C, Artacho R, Giménez R (2006). Beneficial effects of green tea - a review. Journal of the American College of Nutrition 25:79-99.

Chen ZY, Zhu QY, Wong YF, Zhang Z, Chung HY (1998). Stabilizing effect of ascorbic acid on green tea catechins. Journal of Agriculture and Food Chemistry 46:2512-6.

Erba D et al. (2005). Effectiveness of moderate green tea consumption on antioxidative status and plasma lipid profile in humans. The Journal of Nutritional Biochemistry 16:144-9.

Higdon JV, Frei B (2003). Tea catechins and polyphenols: health effects, metabolism, and antioxidant functions. Critical Reviews in Food Science and Nutrition 43:89-143.

Horie H, Mukai T, Kohata K (1997). Simultaneous determination of qualitatively important components in green tea infusions using capillary electrophoresis. Journal of Chromatography A 758: 332-5.

Horie N et al. (2005). Synergistic effect of green tea catechins on cell growth and apoptosis induction in gastric carcinoma cells. Biological \& Pharmacentical Bulletin 28:574-9.

Jeong WS, Kong ANT (2004). Biological properties of monomeric and polymeric catechins: green tea catechins and procyanidins. Pharmaceutical Biology 42 (suppl.):84-93.

Kotani A, Takahashi K, Hakamata H, Kojima S, Kusu F (2007). Attomole catechins determination by capillary liquid chromatography with electrochemical detection. Analytical Sciences 23:157-63.

Kuzuhara T, Sei Y, Yamaguchi K, Suganuma M, Fujiki $\mathrm{H}$ (2006). DNA and RNA as new binding targets of green tea catechins. The Journal of Biological Chemistry 281:17446-56.

Lambert JD, Yang CS (2003). Mechanisms of cancer prevention by tea constituents. The Journal of Nutrition 133:3262S-7S.

Liang H, Liang Y, Dong J, Lu J (2007). Tea extraction methods in relation to control of epimerization of tea catechins. Journal of the Science of Food and Agriculture 87:1748-52.

Liang YR, Ma WY, Lu JL, Wu Y (2001). Comparison of chemical compositions of Ilex latifolia Thumb and Camellia sinensis L. Food Chemistry 75:339-43.
McKay DL, Blumberg JB (2002). The role of tea in human health: an update. Journal of the American College of Nutrition 21:1-13.

Raza H, John A (2007). In vitro protection of reactive oxygen species-induced degradation of lipids, proteins and 2-deoxyribose by tea catechins. Food and Chemical Toxicology 45:1814-20.

Reto M, Figueira ME, Filipe HM, Almeida CMM (2007). Chemical composition of green tea (Camellia sinensis) infusions commercialized in Portugal. Plant Foods for Human Nutrition 62:139-44.

Shimizu M et al. (2005). Epigallocatechin gallate and polyphenon $\mathrm{E}$ inhibit growth and activation of the epidermal growth factor receptor and human epidermal growth factor receptor-2 signaling pathways in human colon cancer cells. Clinical Cancer Research 11:2735-46.

Singh HP, Ravindranath SD, Singh C (1999). Analysis of tea shoot catechins: spectrophotometric quantitation and selective visualization on two-dimensional paper chromatograms using diazotized sulfanilamide. Journal of Agriculture and Food Chemistry 47:1041-5.

Toschi TG et al. (2000). The protective role of different green tea extracts after oxidative damage is related to their catechin composition. Journal of Agriculture and Food Chemistry 48:3973-8.

Wang H, Helliwell K (2000). Epimerisation of catechins in green tea infusions. Food Chemistry 70:33744.

Wang R, Zhou W, Jiang X (2008). Reaction kinetics of degradation and epimerization of epigallocatechin gallate (EGCG) in aqueous system over a wide temperature range. Journal of Agriculture and Food Chemistry 56:2694-701.

Watanabe T, Nishiyama R, Yamamoto A, Nagai S, Terabe $S$ (1998). Simultaneous analysis of individual catechins, caffeine, and ascorbic acid in commercial canned green and black teas by micellar electrokinetic chromatography. Analytical Sciences 14:4358 .

Williamson G, Manach C (2005). Bioavailability and bioefficacy of polyphenols in humans. II. Review of 93 intervention studies. The American Journal of Clinical Nutrition 81:243S-55S.

Wu CD, Wei GX (2002). Tea as a functional food for oral health. Nutrition 18:443-4.

Yao L et al. (2005). Seasonal variations of phenolic compounds in Australia-grown tea (Camellia sinensis). Journal of Agriculture and Food Chemistry 53:6477-83. 